\title{
THEORETICAL AND EXPERIMENTAL ANALYSIS OF LOADING IMPACT FROM THE PROGRESSIVE GEAR ON THE LIFT BRAKING DISTANCE WITH THE USE OF THE FREE FALL METHOD
}

\author{
Paweł Lonkwic ${ }^{1}$, Patryk Różyło² \\ 1 Lift Service S.A. Roztocze str. 6, 20-722 Lublin, Poland, e-mail: plonkwic@gmail.com \\ 2 Lublin University of Technology, Mechanical Engineering Faculty, Department of Machine Design \\ Nadbystrzycka str. 36, 20-618 Lublin
}

Received: 2016.03.06 Accepted: 2016.04.25 Published: 2016.06.01

\begin{abstract}
The gear which is the central safety element of the friction drive lift during braking is exposed to overloading connected with changeable weight which loads the lift braking system. In the article the results of numerical analysis for braking process of CHP 2000 type progressive gear distinguished by an innovative design have been presented. The numerical analysis was conducted with the use of a simulation of the gear roller displacement depending on changeable loading with the support of Abaqus/ CAE software. Displacement of the gear roller from the neutral position in which the gear starts loosing energy of speeding up weight to zero was simulated. The results obtained from computer simulations were verified on the basis of a physical experiment at the bench station created to verify braking parameters of the gears with the use of free fall method.
\end{abstract}

Keywords: friction drive lift, progressive gears, safety, FEA analysis, Abaqus.

\section{INTRODUCTION}

Nowadays, the specific literature regarding the issues of construction, operation of the lifts braking systems and progressive gears does not pay a lot of attention to those subjects. In the publication by [2] the authors use the method of finite elements of Abaqus software to simulate stresses and displacements of instantaneous gear body while braking. The authors in their publication compare the results of numerical analysis with the results of an experiment. The obtained results by means of the experiment in the authors' opinion gave the converging results with the results received via simulation. In the research the authors [7] deal with the aspects connected with the application of neural network to analyze vibrations of the lift operation resulting from changeable weight of transported load. The applied neural networks were used by the authors to evaluate the vibrations symptoms as a result of which a part of the lift or the whole device damage could be stated. The authors in the publication by [5] focus on the concepts consisting in the use of a reduction method to assess the lift operation dynamics. In the presented analyses the lift cabin model has been reduced to the flat system with one, vertical level of freedom.

The demonstrated methodology of reduction was used by the authors to describe a specific mechanism of goods carrying lifts describing presented issues in a mathematical way. Furthermore, the authors in their study analyze what kind of results and parameters of the lift operation have the impact on the characteristics of the lift system accelerations. In the publications $[8,16]$ the authors describe the use of the finite-element method to evaluate the stiffness and resistance of the cabin frames construction 
in different types of the lifts including the gears. The application of FEM method in the described aspects has been used by the authors to optimize the carrying frame construction in terms of the angles reduction of the frame construction beams sections, the reduction of its weight, establishment of safety coefficients and on the basis of received results they made an attempt to determine the places in the lift frame system which are sensitive to damages. The issues connected with dynamics of the lift braking system, analysis of applied materials as well as the gears are touched also in the following research works $[9,10,11,12,13]$. The authors in the above mentioned compilations, among other, focus on the analysis of braking system. They compare the construction as well as the functioning of the gears made by European manufacturers with the newly developed solution.

In the publication by [15] the authors deal with the aspects connected with the influence of the weight of the lift cabin power supply wires and carrying lines in the so called tall lifts working in tall buildings over 40 floors on their operation. In such lifts the significant height of lifting is connected with the fact that it is needed to use a leveling belt which compensates the carrying lines weight as well as the power supply wires. As a result of the above, the remaining assys of the lift are not overloaded excessively. In a model way the authors describe the bahaviour of the leveling belt as well as what is its impact on the linear model of the lift operation. Moreover, they are studying the impact of horizontal displacements of the leveling belt on the system self-vibrations frequency. The information included in the above compilations mainly refers to the issues connected with the lifting device's operation, as well as focuses on other areas of the lifting device work.

With respect to the above, it is justified to prepare numerical models of CHP 2000 type progressive gear and to perform suitable simulations which by means of virtual prototyping will give answer to the question what is the maximum weight capacity for the built construction without bringing any solid damage to it. Furthermore, the authors of the literature $[1,3]$ raise the issues of buckling thin-walled structures and laminated structures using FEM analysis, the results of which are used in various constructions.

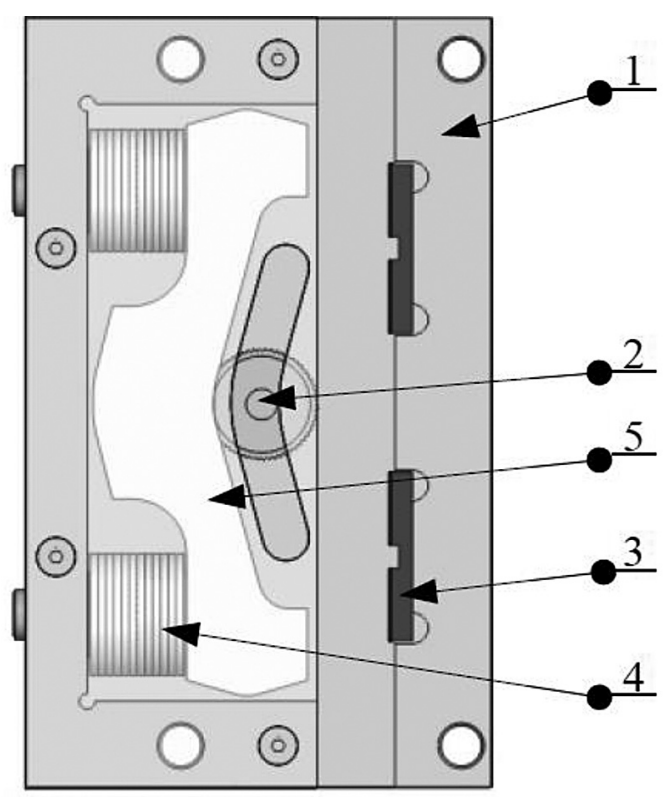

Fig. 1. Diagram of CHP 2000 type progressive gears: 1 - a body, 2 - a braking roller, 3 - a braking plate, 4 - Belleville springs, 5 - a cam [13]

\section{THE IMPACT OF THE GEAR LOADING ON THE BRAKING PROCESS - THEORETICAL CONSIDERATION}

In order to perform theoretical analysis of the aspect, the spatial model of the gear presented in the Figure 1 was created with the use of the module to perform solids modeling included in SolidWORKS program packet.

The innovative construction of CHP 2000 type gear presented in the Figure 1 consist of a body 1 where there is a cam 5 along which the braking roller 2 with knurled surface moves. The packets of Belleville springs 4 with changeable configuration depending on the nominal loading capacity of the lifting device were placed between the cam and the body. During the operation the gear moves along the guide of the lift. The guide is placed in the gear body between the braking roller and the base plates 3 located in the opposite sides of the Belleville springs packets. The variable (continuously variable) set-up of the gear is connected with changeable weight which loads the braking system during operation. With respect to the above, the nominal loading of $\mathrm{F}$ gears is defined by the mathematical relationship (1) [13]:

$$
\mathrm{F}=\mathrm{P}+\mathrm{K}+\mathrm{D}+\mathrm{Q}
$$

where: $\mathrm{P}-$ the cabin weight (a constant parameter) $[\mathrm{N}]$,

$\mathrm{K}$ - the cabin frame weight (a constant 
parameter) $[\mathrm{N}]$,

$\mathrm{D}$ - the weight of cabin doors (a constant parameter) $[\mathrm{N}]$,

$\mathrm{Q}$ - a nominal loading capacity (a changeable parameter) $[\mathrm{N}]$

Theoretical modal analysis is often based on the numerical aspects, which are widely used to verify the dynamics of the construction under testing. With respect to the above, the example of an equation of a mechanical system dynamic movement can be expressed by means of the empirical relationship (2):

$$
\mathrm{f}(\mathrm{t})=|\mathrm{M}|\{\ddot{\mathrm{u}}\}+|\mathrm{C}|\{\dot{\mathrm{u}}\}+|\mathrm{K}|\{\mathrm{u}\}
$$

where: $\{\ddot{\mathrm{u}}\},\{\dot{\mathrm{u}}\} ;\{\mathrm{u}\}$ - represent respectively the following vectors: acceleration, speed and dislocation

$|\mathrm{M}|,|\mathrm{C}|,|\mathrm{k}|$ - represent respectively the following matrices: weight, stiffness and damping

The gear discretization process constituted the main stage of FEM analysis. The contact parameters are based on mutual interaction between subassys in the tangent and regular direction. The accepted friction coefficient between surfaces is 0.3 . The gear braking process was performed on the basis of the static aspects available in Abaqus environment. The investigated system was subject to changeable loading which was applied to the roller. The numerical analysis was conducted including the increasing loading every $2000 \mathrm{~N}$. The numerical analysis was started with the force equal to $4000 \mathrm{~N}$ (out of which $2000 \mathrm{~N}$ refers to the passenger lift weight and $2000 \mathrm{~N}$ to the changeable loading) to $14000 \mathrm{~N}$ as well as with the maximum force of $20000 \mathrm{~N}$. The edge conditions referred to the assignment of indispensable restrains and forces appearing in the mechanism. The body was fully fixed in the space. The possibility to displace along $\mathrm{Y}$ axis, around which the roller has the only chance to rotate, was taken away from both the guide as

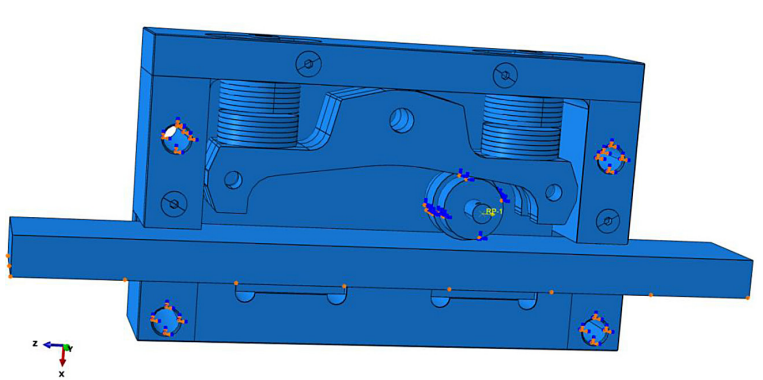

Fig. 2. The edge conditions of the gear system well as from the roller. The relationships appearing in the system are presented in Figure 2.

The operation of the mechanism subject to examination takes place by means of the loading applied to the roller which moves along the cam in the opposite direction to $\mathrm{Z}$ axis and generates the pressure of the guide to the base plates versus $X$ axis. In this way, the braking process on the gear guide was simulated. At the beginning, the roller was just before the contact with the surfaces of the guide and the cam, and immediately after that the loading was applied to it in the form of the force concentrated in one point. The force parameter was connected with the reference point created in the space. In advance, that point was correlated with the milled roller surface to which in fact the loading was applied. The relation of the coupling between the point and the surface was set in Abaqus with the use of the coupling in the module of interaction. The process modeled like that allowed the authors to study the system with changeable loading. Proper course of the numerical simulation was possible due to the fact that suitable FEM mesh was assigned to the model. For that purpose C3D4 four-walled elements as well as C3D8R eightknotted elements (with reduced number of integration points) were used. Reduced integration is one of the techniques to reduce the impact of blockage effect and it is connected with improper forms of the objects deformation. As a result of that operation, the polynomials elements of higher orders are eliminated what has a positive influence on the improvement of the numerical analysis results [8].

A dominating type of the applied mesh was based on the hexagonal structure. Even though the parts partitioning was done, the body and the roller have a mesh with increased concentration but with tetragonal structure. The number of the mesh knots, the total number of the elements and its type have been presented in Figure 3. The results in FEM test were presented in so called integration points, geometrically away from the knot points. The results obtained in the knots are the interpolated results of the values calculated in the points of integration.

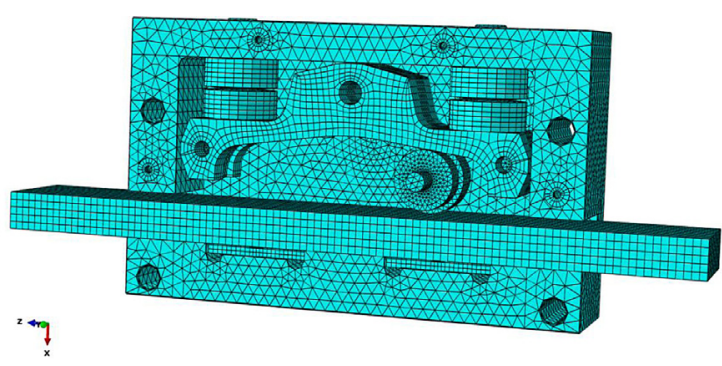

Fig. 3. Model of FEM mesh together with the information about the mesh 


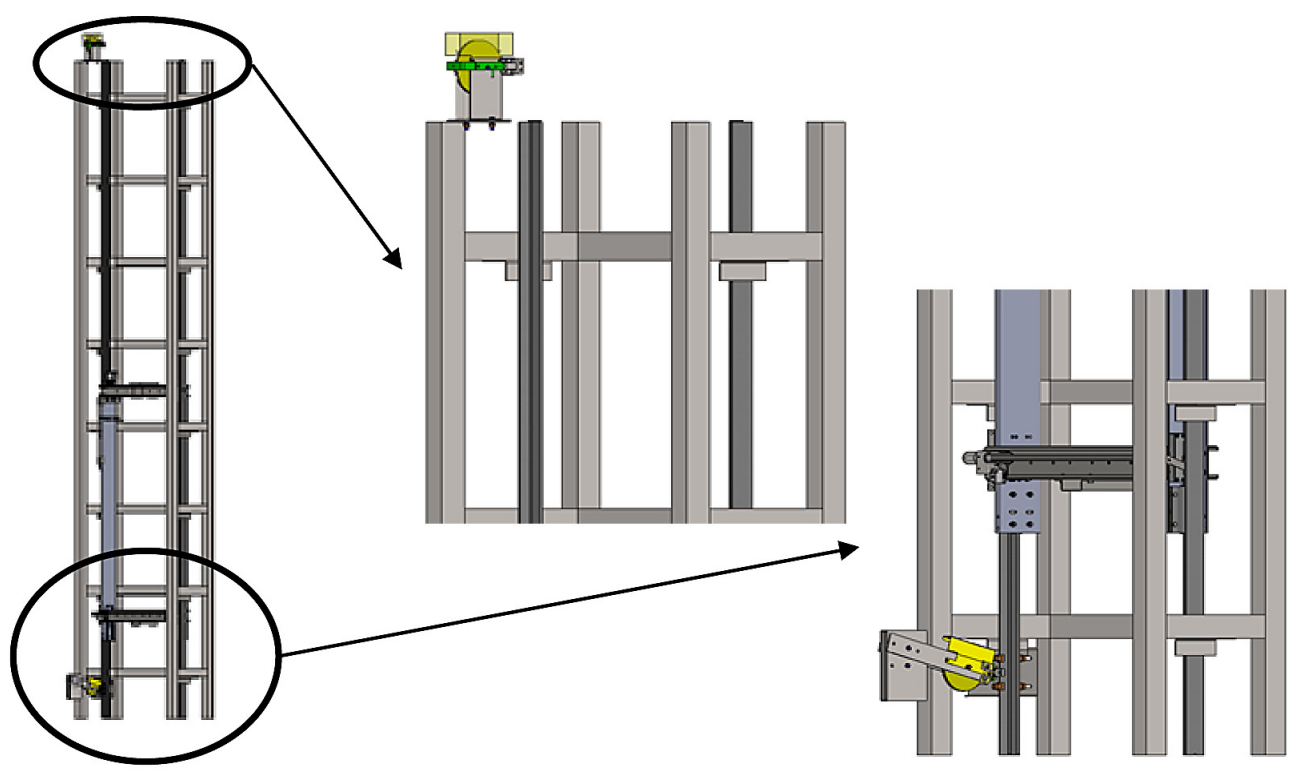

Fig. 4. Model of a test bench to examine the gears with free fall method

\section{CHARACTERISTIC OF TEST BENCH AND TESTING METHODOLOGY}

In order to carry out the tests of the applicable progressive gears, the project and test bench presented in Figure 4 and Figure 5 were prepared.

In order to determine the braking distance, the frame of an investigated braking system was subject to the free fall, in accordance with the conditions included in the standard [14]. The speed of the system free fall was monitored by the braking system consisting, among others, of the speed limiter. During measurements the device was controlling the speed of the tested system on the basis of empirical relationship (3).

$$
v=\sqrt{2 \cdot g \cdot h}
$$

where: $g$ - acceleration of gravity $9,81 \mathrm{~m} / \mathrm{s}^{2}$, $h$ - free fall height measured from the fall starting point to the moment when the speed limiter was activated;

Measurements results of braking distance were obtained by means of taking the average for measurements received after ten successive mea-

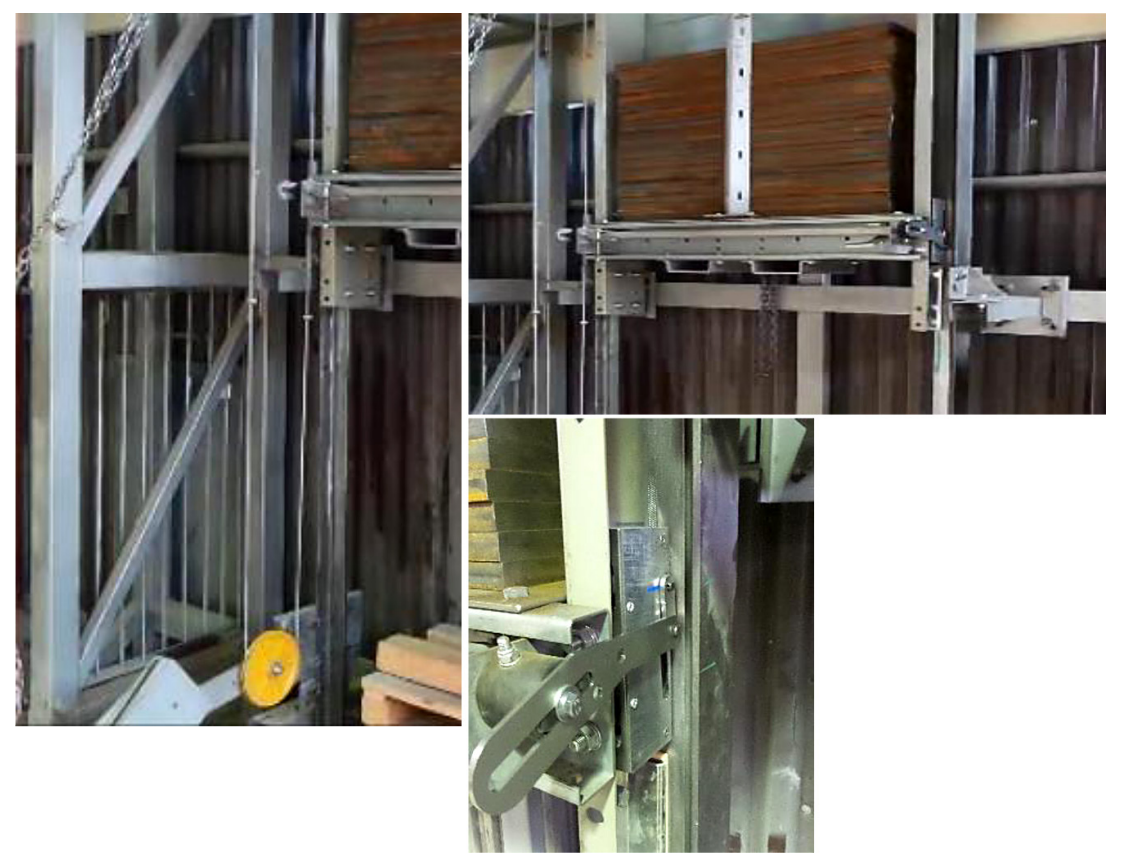

Fig. 5. Test bench to examine the gears with free fall method 
suring tests conducted one after another for the free fall of the tested system. The average value of the conducted measurements was calculated as in the relationship (4).

$$
\bar{Z}=\frac{\sum_{i=1}^{i=k} z_{i}}{k}
$$

where: $z_{i}$ - the maximum braking distance in the consecutive (i) measuring measurement cycle of the frame system free fall,

$k$ - the number of the measurement cycles,

$i$ - the next number of the measurement of the frame system free fall.

\section{CHARACTERISTIC OF TEST BENCH AND TESTING METHODOLOGY}

Tests described in the study were performed in the production shopfloor of the company which manufactures lifting subassys in Lublin. In the below presented Figures the flow of the braking process has been demonstrated depending on the loading obtained by means of computer simulation as well as on the basis of the conducted tests in the created test bench in the conditions of free fall.

In Fig. 6 the results of the simulation conducted for the gear roller during braking process as well as experimental braking distance in the function of changeable loading are presented in a graphical way. The data received by means of simulation was demonstrated as a series of points, whereas data received by means of the experiment was presented as individual points for respective values of loads. The above mentioned data was also described with a regression curve. The models based on the polynomial relations were used in order to determine the regression function. Furthermore, the value of R2 curvilinear regression indicator was also presented. Similar methodology to determine the correlation for the simulation results was demonstrated in Figure 7 in respect to the maximum values received by means of the computer simulation.

In Figure 8 the results of physical experiment are presented. The experiment consists of speed reduction of the moving frame together with a suitable loading. The value of braking distance created as a result of $12000 \mathrm{~N}$ loading has been presented on the left side in Fig. 8. The sign which remained on the guide corresponds to displacement of the gear roller. The sign of braking under $8000 \mathrm{~N}$ loading has been presented on the right side. In both cases the value of braking distance is much higher than the computer simulation. Discrepancies generated as a result of the analyses were caused by a couple of reasons:

- the lack of possibility to simulate the whole system of the frame what would constitute, in that particular case, a model problem;

- the lack of possibility to perform the physical experiment in the way which is close to the computer simulation;

- the lack of possibility to collect the functional imperfection of the actual model in a model way (namely: clearances, delay in operation, wear and tear of braking elements).

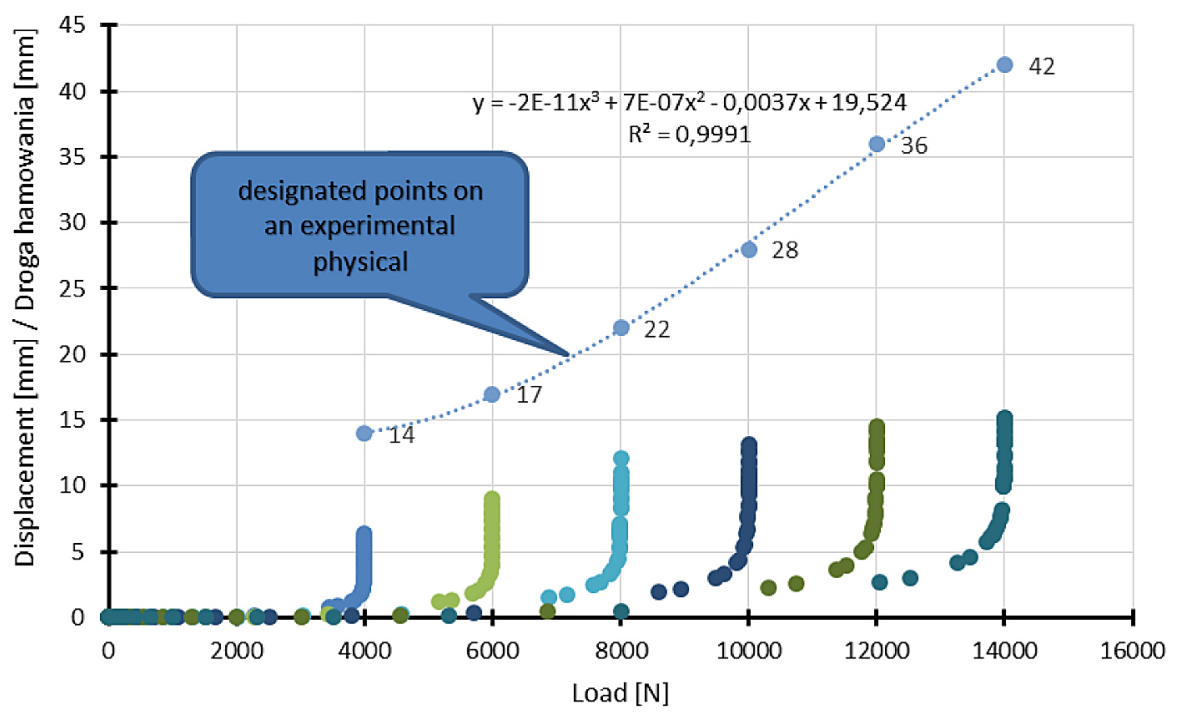

Fig. 6. Diagram of the roller displacements as well as the braking distance in the function of simulated loading of the gear 


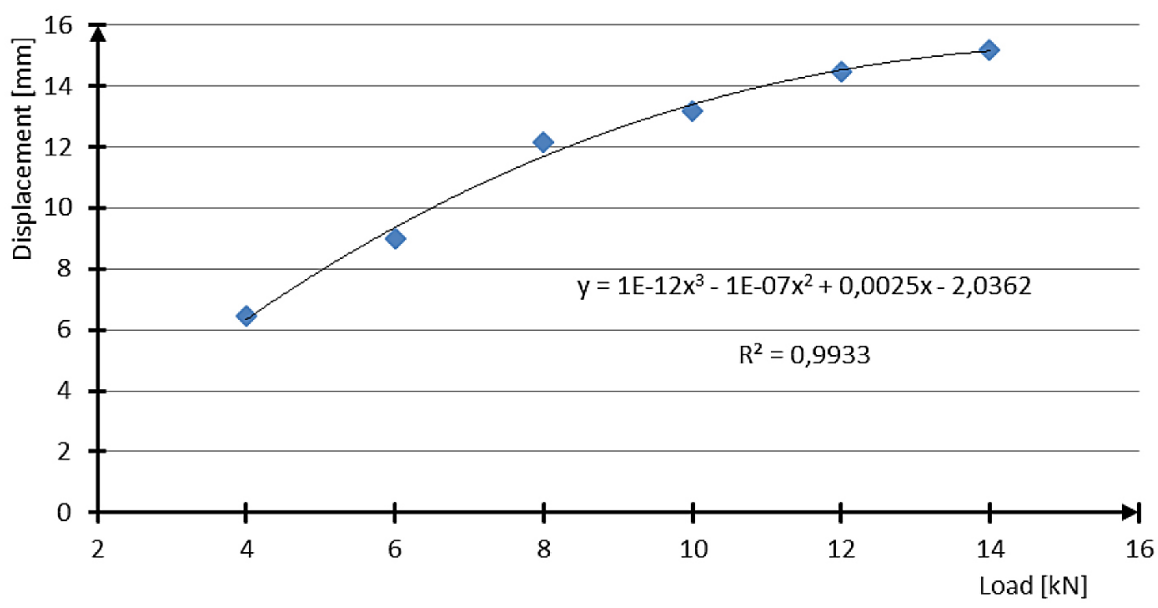

Fig. 7. The loading correlation of the gear and the roller displacement during braking process

With respect to the above, the examples of braking, presented in Figure 8 have some sort of imperfection involved leading, among others, to non-uniform braking distance during the experiment. Even though some divergent data was obtained. The results are satisfying, especially taking into account the fact that the research studies with similar content are missing in the literature.

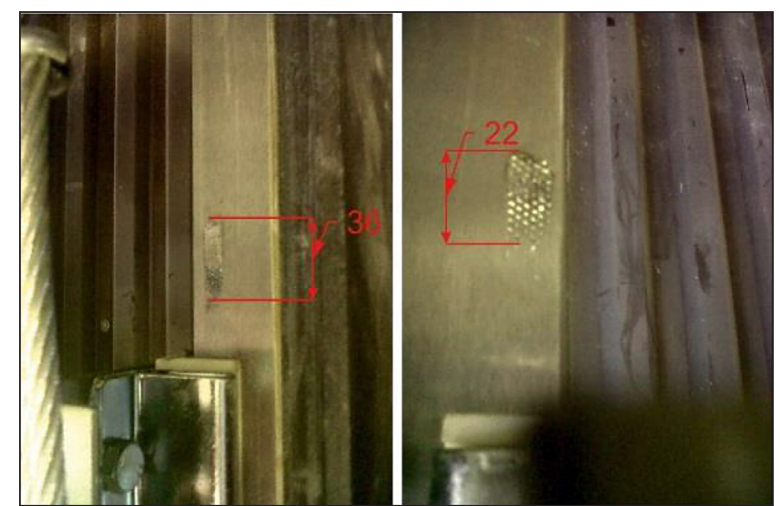

Fig. 8. The physical experiment results in form of the guide signs after completed braking process for the loading of the gear $12000 \mathrm{~N}$ on the left side and 8000 $\mathrm{N}$ on the right side

\section{CONCLUSIONS}

The performed simulating tests and their analysis allow to draw the following final conclusions:

1. Complex phenomena appearing in the scope of operating processes of the braking system do not always allow to create proper mathematical models. Then the attempt to identify the physical model is made on the basis of the observation conducted for the numerical simulation results based on the solid models.

2. When we assume the maximum loading of the gear at the level of $20000 \mathrm{~N}$, then not only the value of loading should be taken into account, but also the value of delay, which is generated by the gear during the braking process. To increase the comfort of the passengers while braking, the value of delay should be within the range from 0,2 to $1 \mathrm{~g}$. Due to the fact that the aspect was touched, it is required to prepare suitable mathematical models including the delay value and the value of stresses presented in the above study on the basis of data received from the described experiment.

3. The numerical analysis proved that significant increase of the force which loads the system does not lead to excessive increase of stresses in the trouble spots. Summing up, similar levels of stresses have been observed in each case of the loading applied to the system, excluding only their changeable character in the range between 2750 to $6000 \mathrm{~N}$. The loading variability results from the fact that in the initial braking process (from the contact of the braking roller with the guide) the value of stresses changes together with the loading and displacement of the roller along the guide. Once the full contact of the roller with the guide is reached, then exclusively the movement due to changeable loading constitutes a variable value, whereas the value of stresses remains in the similar value range.

4. In the fixed working conditions of the lift, the value of loading applied to the gear constitutes half of the assumed values. Moreover, the re- 
sults of the analysis of the simulation conducted for the loading of the maximum value $20000 \mathrm{~N}$ shows that for the maximum loading capacity the gears are able to reduce the energy of moving weight, even though the maximum values of plasticity limit are exceeded. The accepted level of the gear maximum loading does not cause permanent deformation in the elements such as the roller or the gear thrust block thanks to quenching of those elements. Furthermore, in order to eliminate excessive stresses in the cover, when the actual models are being prepared the geometry of the hole which leads the roller should be improved.

5. The increase of the roller displacement together with the loading increase illustrated in the Fig. 6 seems to be confirmed by the general engineering theory. In the further studies regarding the applicable concept, the analysis of the roller displacement impact in terms of its durability and especially the knurled surface which is responsible for the braking process should be conducted. Currently, the lack of accurate literature regarding the work of knurled surfaces requires the preparation of separate simulations and tests.

6. The lack of similar publications dealing with mathematical modeling and simulation modeling with the use of CAx/FEM software described in the literature creates the need to develop the described issue especially in case of the prepared gear with a different construction versus the existing solutions.

7. The innovative construction of the gear gives the chance to take the advantage due to continuously variable set-up of the gear loading and to use small force to unblock the gear once the braking process is completed, what is really important for the lift frame construction.

\section{REFERENCES}

1. Rudawska A., Dębski H., Experimental and numerical analysis of adhesively bonded aluminium alloy sheets joints, Maintenance and Reliability, 2010, 4-10.

2. Kayaoglu E., Salman O., Candas A., Study on Stress and Deformation of an Elevator Safety Gear Brake Block Using Experimental and FEA Meth- ods. Advanced Materials Research, 308-310, 2011, 1513-1518.

3. Dębski H., Kubiak T., Teter A., Buckling and postbuckling behavior of thin-walled composite channel section beam, Composite Structures 100, 2012, 195-204.

4. Taplak H., Erkaya S., Yildirim S., Uzmay I., The Use of Neural Network Predictors for Analyzing the Elevator Vibrations. Mechanical Engineering, 39, 2014, 1157-1170.

5. Jong de J. Understanding the natural behavior of elevator safety gears and their triggering. The International Congress on Vertical transportation technologies Istambul, 2004

6. Filas J., Mudro M., The dynamic equation of motion of driving mechanism of a freight elevator. Procedia Engineering, 48, 2012, 149-152.

7. Feng L., Bao Y., Zhou X., Wang Y., High Speed Elevator Car Frame's Finite Elements Analysis. Advanced Materials Research, 510, 2010, 298-303.

8. Zienkiewicz O.C., Taylor R.L., Finite Element Method, 5th Edition, Volume 2 - SolidMechanics, Elsevier, 2000.

9. Lonkwic P., Szydło K., Longwic R., Lotko W., Analysis of the system dynamics intended to tighten the speed limiter line in the passenger lifts - XIth Secientific \& Technical Conference LOGITRANS, 2014.

10. Lonkwic P., Szydło K., Longwic R., Lotko W. Testing methodology of main progressive gears - XIth Secientific \& Technical Conference LOGITRANS, 2014.

11. Lonkwic P., Szydło K. Selected Parameters of the Work of Speed Limiter Line Straining System in a Frictional Lift. Advances in Science and Technology, 8 (21), 2014, 73-77.

12. Lonkwic P., Gardyński L. Testing polymer rollers memory in the context of passenger lift car comfort. Journal of Vibroegineering, 1, 2014, 225-230.

13. Lonkwic P. Using disk spring solver application for prototyping disk spring in passenger lift catchers. Applied Computer Science, 10, 2014, 67-74.

14. Polish Standard PN EN 81.1+A3, Safety Regulations Concerning the Structure and Installation of Lifts, Part I. Electric Lifts.

15. Zhu W. D., Ren H., A linear model of stationary elevator traveling and compensation cables. Journal of Sound and Vibration, 332, 2013, 3086-3097.

16. Onur Y. A., Imrak C. E., Reliability analysis of elevator car frame using analytical and finite element methods. Building Services Engineering Research \& Technology, 33 (3), 2012, 293-305. 